\title{
Gestão de custos e formação de preço de venda, gestão de caixa e gestão de riscos: um estudo exploratório no arranjo produtivo local gesseiro do estado de Pernambuco
}

\begin{abstract}
Lucivaldo Lourenço da Silva Filho Mestrado em Ciências Contábeis pela Universidade Federal de Pernambuco - UFPE Professor da Faculdade Santa Catarina - FASC Estrada do Arraial, 2740. Tamarineira. Recife/PE. CEP: 52051-380

E-mail: lucivaldolourenco@gmail.com

Umbelina Cravo Teixeira Lagioia Doutorado em Administração pela Universidade Federal de Pernambuco - UFPE Professora da Universidade Federal de Pernambuco - UFPE Av. Prof. Moraes Rego, 1235. Cidade Universitária. Recife/PE. CEP: 50670-901 E-mail: umbelinalagioia@gmail.com

João Gabriel Nascimento de Araújo Mestrado em Ciências Contábeis pela Universidade Federal de Pernambuco - UFPE Professor da Faculdade Santa Helena - FSH Av. Caxangá, 990. Zumbi. Recife/PE. CEP: 50711-095 E-mail:j_gabriel90@hotmail.com

Juliana Gonçalves de Araujo Doutorado em andamento em Administração pela Universidade Federal de Pernambuco - UFPE Professora da Faculdade Santa Helena - FSH Av. Caxangá, 990. Zumbi. Recife/PE. CEP: 50711-095 E-mail: juhliana.araujo@gmail.com

Francisco de Assis Carlos Filho Doutorado em andamento em Administração e Controladoria pela Universidade Federal do Ceará - UFC Professor da Universidade de Pernambuco - UPE Avenida Agamenon Magalhães, S/N. Santo Amaro. Recife/PE. CEP: 50100-010 E-mail: francisco.assis.filho@gmail.com
\end{abstract}

\section{RESUMO}

Esta pesquisa teve como objetivo geral investigar se os gestores do APL gesseiro de Pernambuco conhecem, atribuem importância e utilizam informações para a tomada de decisão, decorrentes da Gestão de Custos e Formação de Preços de Vendas, Gestão de Risco Operacional e Gestão de Caixa. O estudo caracterizou-se como exploratório e fez-se uso das análises descritiva e inferencial. Os dados foram coletados por meio da aplicação de questionários in loco, na qual se obteve a participação de 53 empresas. Identificou-se que os gestores das empresas pertencentes ao APL gesseiro não 
Gestão de custos e formação de preço de venda, gestão de caixa e gestão de riscos: um estudo exploratório no arranjo produtivo local gesseiro do estado de Pernambuco Lucivaldo Lourenço da Silva Filho, Umbelina Cravo Teixeira Lagioia, João Gabriel Nascimento de Araújo, Juliana Gonçalves de Araujo, Francisco de Assis Carlos Filho

conhecem os conceitos de custo, disponibilidade de caixa, e risco operacional, no entanto, atribuem um alto grau de importância para as informações geradas, e essas empresas de maneira geral utilizam a gestão de custos e formação do preço de venda, gestão de caixa e gestão de risco operacional em seu processo de tomada de tomada de decisão.

Palavras-chave: Arranjo Produtivo Local. Polo gesseiro. Gestão de custos e formação de preço de venda. Gestão de caixa. Gestão de risco operacional.

\section{Cost management and formation of sale price, cash management and risk management: an exploratory study on plasterer of Pernambuco state's cluster}

\section{ABSTRACT}

This research aimed to investigate whether managers of plasterer Pernambuco's cluster know, attribute importance and use information for decision making, resulting from Management Costs and Price Formation of Sales, Operational Risk Management and Cash Management. The study was characterized as exploratory and made use of descriptive and inferential analyzes. Data were collected through surveys in loco, which was obtained in the participation of 53 companies. It was identified that the managers of the companies belonging to the plasterer cluster don't know the concepts of cost, cash availability, and operational risk, however, attach a high degree of importance to the data generated, and these companies generally use management costs and training of the sales price, cash management and operational risk management in the process of making decisions.

Keywords: Cluster plasterer polo. Cost management. Training of the sales price. Cash management. Operational risk management.

\section{INTRODUÇÃO}

O Arranjo Produtivo Local (APL) caracteriza-se por um aglomerado de empreendimentos em determinado território com indivíduos que atuam em torno de uma atividade produtiva predominante, compartilhando formas de cooperação e algum mecanismo de governança, e pode incluir pequenas, médias e grandes empresas. (MDIC, 2006; REDESIST, 2012). 
Gestão de custos e formação de preço de venda, gestão de caixa e gestão de riscos: um estudo exploratório no arranjo produtivo local gesseiro do estado de Pernambuco Lucivaldo Lourenço da Silva Filho, Umbelina Cravo Teixeira Lagioia, João Gabriel Nascimento de Araújo, Juliana Gonçalves de Araujo, Francisco de Assis Carlos Filho

Como a atividade se consolida numa região, a criação de um APL atrai investimentos, geralmente cria ou reforça a aglomeração de empresas, proporciona elevação da renda e induz investimentos públicos em infraestrutura (SANTOS; DINIZ; BARBOSA, 2004).

A origem do APL não é recente, remonta há mais de um século e baseia-se nas ideias de Alfred Marshall (1890) sobre regiões de desenvolvimento têxteis e metal mecânica da Alemanha, Inglaterra e França. O entendimento de Marshall se baseava na formação das "fazendas industriais", tais fazendas poderiam proporcionar uma redução de custos, à medida que o conjunto maquinário utilizado seria específico, economizando recursos e evitando desperdícios, tornando-se viável a utilização de subprodutos.

São encontrados vários APL's no Estado de Pernambuco, um deles é o gesseiro, que será objeto de estudo desta pesquisa. Este APL é relevante em virtude de ser considerado como o maior polo gesseiro do Brasil, chegando a produzir $95 \%$ do total da produção nacional. As empresas deste APL oferecem cerca de 13.200 empregos diretos e aproximadamente 66.000 indiretos, sendo estas de diversos portes, desde micro e pequeno a empresas de médio porte (SINDUSGESSO, 2012). Entretanto, ressalta-se que no decorrer da pesquisa também foi observada a existência de empresas de grande porte, de acordo com os critérios de faturamento adotados pela Receita Federal.

Independente do porte faz-se necessário, para a continuidade dessas entidades, uma boa gestão, e, em seu processo, a tomada de decisão é realizada constantemente em todos os níveis da empresa. Para a tomada de uma decisão o gestor precisa ser subsidiado por informações que o possibilitem a percepção de qual a melhor atitude a ser tomada.

Hall et al. (2012) enfatizam que a contabilidade por meio de suas ferramentas, ou de seus instrumentos de subsídio à gestão, é capaz de contribuir na redução da mortalidade das pequenas empresas. A partir de constatações empíricas, os referidos autores identificaram que os empresários utilizam as informações contábeis muito 
Gestão de custos e formação de preço de venda, gestão de caixa e gestão de riscos: um estudo exploratório no arranjo produtivo local gesseiro do estado de Pernambuco Lucivaldo Lourenço da Silva Filho, Umbelina Cravo Teixeira Lagioia, João Gabriel Nascimento de Araújo, Juliana Gonçalves de Araujo, Francisco de Assis Carlos Filho

timidamente, sendo suas decisões baseadas mais no conhecimento do negócio do que nestas informações. Pelissari, Vanalle e Gonçalvez (2006) também constataram que $40 \%$ dos gestores de micro e pequenas empresas tomam decisões estratégicas com base em suas experiências ou de terceiros.

Caso este comportamento seja identificado no APL gesseiro pode influenciar na sobrevivência das empresas deste arranjo. Visto que, o atual ambiente de negócios está cada vez mais interdependente e caracterizado pelo elevado grau de mudança e incerteza, assim, é relevante a utilização das informações geradas pela contabilidade na gestão empresarial.

Neste cenário, observa-se a necessidade dos proprietários e dos gerentes de conhecerem os seus empreendimentos com a finalidade de entender e controlar efetivamente seus resultados, situação financeira, riscos operacionais, atividade econômica e necessidade de investimentos.

Diante do que foi exposto, o estudo tem como objetivo responder ao seguinte questionamento: Os proprietários/gestores do APL gesseiro do Estado de Pernambuco conhecem, atribuem importância e utilizam as informações advindas da gestão de custos e formação de preços de vendas, gestão de caixa e gestão de risco operacional na tomada de decisão gerencial?

\section{REFERENCIAL TEÓRICO}

\subsection{Arranjo Produtivo Local}

Arranjos Produtivos Locais (APL), segundo o Ministério do Desenvolvimento, Indústria e Comércio Exterior - MDIC (2012) são grupos territoriais de agentes econômicos, políticos e sociais que possuem os seus objetivos voltados para um segmento de atividade econômica, envolvendo interações entre as entidades relacionadas. Estes grupos podem ser fornecedores, produtores de bens e serviços ou comercializadores, e envolvem uma cadeia de interessados no ramo da atividade econômica estabelecido. 
Gestão de custos e formação de preço de venda, gestão de caixa e gestão de riscos: um estudo exploratório no arranjo produtivo local gesseiro do estado de Pernambuco Lucivaldo Lourenço da Silva Filho, Umbelina Cravo Teixeira Lagioia, João Gabriel Nascimento de Araújo, Juliana Gonçalves de Araujo, Francisco de Assis Carlos Filho

Essas aglomerações de empresas em áreas geográficas com objetivos voltados a uma atividade econômica são objetos de estudo e debate em diversas áreas do conhecimento. No entanto, a referência histórica para os estudos relacionados a estas aglomerações é Alfred Marshall (1890), que segundo Kukalis (2010) foi o primeiro estudioso a investigar a concentração de comércios especializados em certas localidades.

De acordo com Stainsack (2005), um APL deve ter uma quantidade significativa de empreendimentos e indivíduos que operam sob uma atividade produtiva e atuam em um mesmo território, e atuam compartilhando o conhecimento percebido da cooperação e mecanismo de governança, podendo ter empresas de pequeno, médio e grande porte.

Devido aos benefícios gerados por um APL, conforme Galdámez, Carpinetti, e Gerolamo (2009) há uma tendência dos países promoverem a concentração de Pequenas e Médias Empresas (PMEs) que atuam sob o mesmo tipo de negócio ou atividade econômica, e este fenômeno de aglomerações de PMEs é denominado na literatura como cluster, no entanto, os autores ressaltam que o termo mais comum no Brasil é o de Arranjo Produtivo Local (APL).

Porter (1998) conceitua cluster como um agrupamento geograficamente concentrado de empresas inter-relacionadas e instituições correlatas numa determinada área, vinculadas por elementos comuns ou complementares. Mas que conforme o autor esta concentração pede contemplar apenas uma cidade, cidades vizinhas, uma região de um país, todo o país, ou até uma rede de países próximos.

Seja considerado APL ou cluster, Matos e Machado (2013) consideram ambas como novas formas organizacionais que podem possibilitar as micro e pequenas empresas a conseguir ganhos em economias de escala de escopo, devido elas se tornarem altamente competitivas.

Diversos trabalhos abordaram essa temática, tais como Sörvell (2007), Galdámez, Carpinetti e Gerolamo (2009), Vilela Junior (2010), Diez-Vial (2011). Observando o contexto brasileiro, Correia, Mariani e Ferreira (2012) e Matos e Machado 
Gestão de custos e formação de preço de venda, gestão de caixa e gestão de riscos: um estudo exploratório no arranjo produtivo local gesseiro do estado de Pernambuco Lucivaldo Lourenço da Silva Filho, Umbelina Cravo Teixeira Lagioia, João Gabriel Nascimento de Araújo, Juliana Gonçalves de Araujo, Francisco de Assis Carlos Filho

(2013). Nesses estudos, são observados diversos benefícios provenientes da prática de atuação produtiva e econômica em formato de APL, contudo, também se identifica alguns procedimentos inadequados que podem prejudicar as empresas destes arranjos.

\subsubsection{Arranjo Produtivo Local Gesseiro}

O estado pioneiro no país na produção gipsita e de gesso foi o Rio Grande do Norte, que iniciou suas atividades em 1938 e conseguiu o monopólio deste mercado durante 20 anos (CUNHA, et al., 2008). Contudo, na década de 60, Pernambuco assumiu a posição de maior produtor nacional e mantém esta posição até hoje (SINDUSGESSO, 2012).

O Polo Gesseiro do Estado de Pernambuco compreende as cidades de Araripina, Ipubí, Ouricuri, Bodocó e Trindade, as quais ficam situadas no extremo oeste do Estado, sendo equidistantes cerca de $800 \mathrm{~km}$ das principais capitais (Recife, Salvador, Fortaleza, Aracaju, Maceió, João Pessoa e Natal) (SINDUSGESSO, 2012).

Este polo é considerado tanto em âmbito estadual quanto federal como Arranjo Produtivo Local-APL. Ele tem uma reserva estimada 1,22 bilhão de toneladas o que corresponde a uma das reservas mais expressivas do mundo e a maior medida no Brasil (FALCÃO, 2009).

A produção de gesso desta região quando comparada a produção mundial, chega a cerca de $45 \%$ da produção mundial de gesso, fazendo com que essa região seja considerada uma das maiores jazidas do mundo (ANDRADE; FARIAS; MOUTINHO, 2013).

O polo gesseiro além de ser considerado um APL pelos entes públicos, e ser o maior produtor do gesso consumido no país, as jazidas de minério da região do Araripe uma excelente condição de mineração, assim como, também tem o minério de melhor qualidade do mundo, segundo Luz e Lins (2005). Desse modo, percebe-se que além de sua reconhecida importância e grande capacidade de exploração, este arranjo também oferece uma qualidade de seus produtos que podem abrir novos mercados consumidores. 
Gestão de custos e formação de preço de venda, gestão de caixa e gestão de riscos: um estudo exploratório no arranjo produtivo local gesseiro do estado de Pernambuco Lucivaldo Lourenço da Silva Filho, Umbelina Cravo Teixeira Lagioia, João Gabriel Nascimento de Araújo, Juliana Gonçalves de Araujo, Francisco de Assis Carlos Filho

\subsection{Utilização das Variáveis de Pesquisa}

A contabilidade e a gestão são interligadas, e as suas técnicas quando utilizadas são úteis não apenas para o atendimento das obrigações fiscais e trabalhistas, mas principalmente no processo de tomada de decisão, proporcionando prever problemas, permitindo com que os gestores solucionem possíveis problemas tomando medidas preventivas (HALL et al., 2012)

Dentre as diversas funções e ferramentas que possui a contabilidade, foram escolhidas como objeto de estudo desta pesquisa a gestão de custo e formação de preço de venda, a gestão de caixa e a gestão de risco operacional.

\subsubsection{Gestão de Custos e Formação de Preços de Venda}

A competente gestão da contabilidade de custos melhora a qualidade das decisões, auxiliam no controle dos processos da empresa dando visibilidade as imperfeições, consequentemente torna a atividade mais competitiva.

Crepaldi (2008) lembra que preços definidos exclusivamente pelo mercado são um risco e que os custos devem ser baseados no valor que o cliente está disposto a pagar pelo produto, ou seja, partir do preço para se chegar ao custo.

Tomando por base as considerações de custo para formação de preço, Crepaldi (2008) elenca: (1) custo pleno; (2) custo de transformação; (3) custo marginal; e o (4) rendimento sobre o capital empregado, como sendo os principais métodos para determinação do preço de venda. A opção por qualquer dos métodos vai variar em função dos objetivos fixados pela empresa, que o definirá visando ao atendimento de suas expectativas.

$\mathrm{Na}$ literatura são conhecidos vários sistemas de custeio, que contribuem para a formação do preço de venda e para a gestão no negócio, tais como: custeio por absorção, custeio direto ou variável, custeio pleno ou integral, custeio padrão, a unidade de esforço de produção e custeio baseado em atividades (MARION, 1996; SANTOS, 1999; MAHER, 2001; MARTINS 2008). 
Gestão de custos e formação de preço de venda, gestão de caixa e gestão de riscos: um estudo exploratório no arranjo produtivo local gesseiro do estado de Pernambuco Lucivaldo Lourenço da Silva Filho, Umbelina Cravo Teixeira Lagioia, João Gabriel Nascimento de Araújo, Juliana Gonçalves de Araujo, Francisco de Assis Carlos Filho

No tocante a formação de preços, o conhecimento dos custos se faz vital, no entanto, isso não basta, pois existem outros fatores que influenciam na formação dos preços. Os administradores da empresa devem ter o entendimento pleno do mecanismo do mercado o qual a entidade está inserida e alinhar tal entendimento a gestão de custos e as estratégias definidas pela mesma para a formação do preço de venda.

Martins (2008) defende que, para administrar preços de venda, sem dúvida é necessário conhecer o custo do produto; porém essa informação, por si só, embora seja necessária, não é suficiente. Além do custo, é preciso saber o grau de elasticidade da demanda, os preços de produtos dos concorrentes, os preços de produtos substitutos, as estratégias de marketing da empresa etc.; e tudo isso depende também do tipo de mercado em que a empresa atua, que vai desde o monopólio até a concorrência perfeita, mercado de commodities etc.

Outra variável proposta é a formação de preço, que segundo Reis e Santana (2012) o preço de venda tem que suprir as necessidades da empresa e ser atrativo para os consumidores, pois a má formação do preço faz com que a empresa fique vulnerável à possibilidade de falência.

Contudo, conforme Oliveira e Alves (2012) o processo de apreçamento não é uma atividade padronizada, e necessita de uma análise especial para cada produto e cada circunstância, e devem ser levados em consideração os fatores que irão influenciar na definição do preço final, deste modo, o referido autor ressalta que o preço deve ser baseado em custos, concorrência ou baseado em valor.

Preços baseados em custos é aquele em que o gestor precisa apenas conhecer o seu custo, e no qual, não necessita saber a demanda do seu produto (DIAS, 2006). Já os preços baseados na concorrência são aqueles em que as empresas levam em consideração os preços praticados pelos seus concorrentes que vendem produtos similares ou substitutos, e os preços baseados no valor, são aqueles em que a empresa busca conhecer o que o cliente deseja e qual o preço de mercado do produto que ele deseja (OLIVEIRA; ALVES, 2012). 
Gestão de custos e formação de preço de venda, gestão de caixa e gestão de riscos: um estudo exploratório no arranjo produtivo local gesseiro do estado de Pernambuco Lucivaldo Lourenço da Silva Filho, Umbelina Cravo Teixeira Lagioia, João Gabriel Nascimento de Araújo, Juliana Gonçalves de Araujo, Francisco de Assis Carlos Filho

\subsubsection{Gestão de Caixa}

A gestão do caixa está diretamente relacionada à administração de recursos de alta liquidez, estes se apresentando em forma de espécie ou em contas bancárias. Diversos autores (FREZATTI, 1997; BRAGA, 1995; HOJI, 2003; SANVICENTE, 1997; GITMAN, 2001) associam à conceituação do termo "caixa" como o recurso que se apresenta de forma mais líquida e disponível na entidade, muitas vezes sendo numerários representados em forma de cédulas e moedas metálicas. Esta classificação de ativos tem a característica de serem usados prontamente em caso de eventual necessidade e uma má gestão destes recursos podem acarretar insolvência para a entidade.

A informação sobre a gestão do caixa é tão relevante, que em casos de empresas que reportem relatórios contábil-financeiros, esta é útil para tomada de decisões e análises sobre a capacidade de a entidade solver com suas obrigações, isto sendo de interesse direto dos seus credores.

No caso das micro e pequenas empresas a gestão do caixa torna-se ainda mais relevante, pois estas não necessitam elaborar relatórios para atendimento a usuários externos como as sociedades anônimas. Portanto, elas utilizam prioritariamente relatórios de cunho gerencial, a fim de controlar e planejar seus recursos da maneira mais eficiente e eficaz, assim, por não possuírem tantos recursos ou ativos e passivos em longo prazo, pequenas empresas tendem a ter de possuir mais liquidez para atender aos eventos e transações rotineiras (MATIAS; LOPES JÚNIOR, 2002).

No entanto, os aspectos intrínsecos ao gerenciamento do caixa tem bastante relevância nas empresas de capital aberto, atribuindo importância para a demonstração do fluxo de caixa e consequentemente para o mercado de capitais e seus investidores. Diversos estudos foram realizados observando o fluxo de caixa de entidades listadas na BM\&FBovespa a fim de também estimar entradas de recursos líquidos levando em consideração os riscos inerentes. Exemplo deste estudo é exposto por Oliveira, Ramalho e Moura (2013) onde os mesmos buscaram analisar a qualidade da gestão do 
Gestão de custos e formação de preço de venda, gestão de caixa e gestão de riscos: um estudo exploratório no arranjo produtivo local gesseiro do estado de Pernambuco Lucivaldo Lourenço da Silva Filho, Umbelina Cravo Teixeira Lagioia, João Gabriel Nascimento de Araújo, Juliana Gonçalves de Araujo, Francisco de Assis Carlos Filho

capital de giro líquido e sua gestão de caixa levando em consideração os fluxos de caixa em risco.

A gestão de caixa realizada através da demonstração contábil também possibilita o desenvolvimento de uma análise que, segundo Plewa e Friedlob (1995), visa atender às seguintes funções: acelerar os recebimentos e concentração de fundos; planejar e protelar os desembolsos; provisionar as entradas e saídas de dinheiro; investir recursos ociosos; reportar os saldos de caixa; e, por fim, monitorar o fluxo de caixa.

Outros estudos relatam a importância da análise e interpretação da Demonstração dos Fluxos de Caixa para identificação da fase do ciclo de vida de uma entidade, assim como possibilita, também, a identificação do setor econômico em que a empresa se encontra, como é citado por Stickney e Weil (2001) e por Marques et al. (2008).

\subsubsection{Gestão de Risco Operacional}

O risco para a maioria das pessoas é a probabilidade de se obter resultados ruins nos "jogos da vida". Como por exemplo, ao dirigir um carro em alta velocidade, há o risco de sofrer um acidente, de receber uma multa. O risco tem uma conotação quase inteiramente negativa. Mas, em finanças o conceito de risco é bem mais abrangente, porque ele inclui não exclusivamente os resultados indesejáveis, mas também os bons resultados, que seria o retorno acima do inicialmente esperado (DAMODARAN, 2010).

A visão tradicional do risco é um conceito que é amplamente discutido na literatura de finanças, (JORION, 2003; DAMODARAN, 2004; ASSAF NETO, 2009), mas também é utilizado na controladoria como uma das ferramentas que possibilita a identificação de riscos cujo podem/poderiam influenciar no resultado das empresas (PADOVEZE, 2011)

Assaf Neto (2009, p.215) afirma que "o risco pode ser entendido pela capacidade de se mensurar o estado de incerteza de uma decisão mediante o conhecimento das probabilidades associadas à ocorrência de determinados resultados ou valores". 
Gestão de custos e formação de preço de venda, gestão de caixa e gestão de riscos: um estudo exploratório no arranjo produtivo local gesseiro do estado de Pernambuco Lucivaldo Lourenço da Silva Filho, Umbelina Cravo Teixeira Lagioia, João Gabriel Nascimento de Araújo, Juliana Gonçalves de Araujo, Francisco de Assis Carlos Filho

Para Padoveze (2011, p. 135 e 136) o conceito geral de risco é "definido como eventos futuros incertos, que podem influenciar o alcance dos objetivos estratégicos, operacionais e financeiros da organização". Para tanto o autor propõe a gestão dos riscos da empresa, cujo foco seria o de manter um processo sustentável de criação de valor para os acionistas, uma vez que qualquer negócio sempre está exposto a um conjunto de riscos.

Ainda de acordo com Padoveze (2011), para a consecução da gestão de risco se faz necessário criar uma "arquitetura informacional" para monitorar a exposição da empresa ao risco. O autor defende a relação sistêmica do ambiente externo e interno, no qual, é considerado o ambiente interno, quando a gestão do risco percebe o risco em uma perspectiva de conformidade, e o ambiente externo percebendo o risco como uma perspectiva de desempenho.

O risco operacional está relacionado a possíveis perdas relativas à má gestão operacional, seja como resultado de sistemas e/ou controles inadequados, falhas de gerenciamento e erros humanos (JORION, 2003). Deste modo, Duarte (2001) define que o risco operacional é uma medida das possíveis perdas em uma instituição caso seus sistemas, práticas e medidas de controle não sejam capazes de resistir a falhas humanas ou situações adversas de mercado.

Brasiliano (2003) classifica 16 (dezesseis) tipos de riscos operacionais em 4 (quatro) subáreas, classificando-os se estão relacionados a proteção do patrimônio, a segurança das informações, a administração dos recursos humanos, ou riscos provocados pela atividade fim da organização e suas estratégias. São elas: Riscos relacionados à proteção patrimonial: risco de overload, risco de obsolescência, risco de equipamento e risco de catástrofe; Riscos relacionados à segurança das informações: risco de presteza e confiabilidade e risco de modelagem; Riscos decorrentes diretamente da administração dos recursos humanos: risco de erro não intencional, risco de fraudes e risco de qualificação; e Riscos provocados pela atividade fim da organização e suas estratégias: risco de produtos e serviços, risco de regulamentação, risco de liquidação financeira, risco sistêmico, risco de concentração, risco de imagem. 
Gestão de custos e formação de preço de venda, gestão de caixa e gestão de riscos: um estudo exploratório no arranjo produtivo local gesseiro do estado de Pernambuco Lucivaldo Lourenço da Silva Filho, Umbelina Cravo Teixeira Lagioia, João Gabriel Nascimento de Araújo, Juliana Gonçalves de Araujo, Francisco de Assis Carlos Filho

Esta indicação da quantidade de categoria de riscos coaduna com Marshall (2002), que defende que o risco operacional é bem amplo e abrangente devido à grande quantidade de situações em que as entidades estão expostas, do ponto de vista operacional.

\section{METODOLOGIA}

A produção científica com foco em arranjos produtivos locais do estado de Pernambuco é escassa (ANDRADE; FARIAS; MOUTINHO, 2013). Desse modo, em função dos objetivos deste estudo, a pesquisa é classificada como exploratória e descritiva.

Exploratória, devido essa modalidade de pesquisa permitirum aprofundamento acerca do conhecimento do tema abordado, tornando-o mais claro, pois pesquisas exploratórias são úteis para a abordagem de temas pouco explorados (MUNARETTO, CORRÊA; CUNHA, 2013).

Descritiva, pois segundo Gil (2002, p. 42) essa modalidade de pesquisa tem como principal objetivo "a descrição das características de determinada população ou fenômeno", e também será classificada como pesquisa descritiva os estudos que visam a descoberta de associações entre variáveis.

Esta pesquisa também é caracterizada como quantitativa. Para Dantas et al. (2011) uma pesquisa caracteriza-se como quantitativa devido a utilização de técnicas estatísticas ou econométricas que cheguem a superar a necessidade da simples necessidade de utilização de medidas descritivas referente a determinada situação.

A pesquisa teve como população as empresas situadas no arranjo produtivo local gesseiro do estado de Pernambuco composto pelas cidades de Araripina, Trindade, Ipubi, Ouricuri e Bodocó. Obteve-se a participação de 53 empresas que se disponibilizaram a responder o questionário de pesquisa. Salienta-se que inicialmente foi utilizada uma lista das empresas de gesso associadas à Federação das Indústrias do Estado de Pernambuco (FIEPE). A partir dessa lista, foram realizados contatos para 
Gestão de custos e formação de preço de venda, gestão de caixa e gestão de riscos: um estudo exploratório no arranjo produtivo local gesseiro do estado de Pernambuco Lucivaldo Lourenço da Silva Filho, Umbelina Cravo Teixeira Lagioia, João Gabriel Nascimento de Araújo, Juliana Gonçalves de Araujo, Francisco de Assis Carlos Filho

a realização de agendamentos por telefone e e-mails, no entanto, parte significativa dos dados não estava atualizada, o que inviabilizou o agendamento com todas as empresas associadas.

Não há um consenso da quantidade de empresas participantes do Arranjo Produtivo Local gesseiro. A lista da FIEPE, utilizada por esse estudo, é uma das fontes que se pode obter informações sobre empresas cadastradas, no entanto, a população não é definida, haja vista que outras empresas do polo gesseiro podem não estar associadas à FIEPE, ocasionando uma dificuldade na apresentação de participação da amostra na população.

Assim, conforme Guimarães (2012) este estudo faz o uso de uma amostragem por conveniência, também chamado de amostragem não probabilística, uma vez que a amostra foi formada por elementos que o pesquisador reuniu simplesmente porque dispunha deles.

A coleta dos dados realizou-se por meio da aplicação de questionário juntos aos proprietários/gestores das empresas pesquisadas, sendo coletados in loco pelo próprio pesquisador durante o mês de agosto de 2013. O instrumento de coleta de dados utilizado foi dividido em dois grupos. No primeiro, estão contidas as informações socioeconômicas do respondente e da empresa (cargo, formação, tempo de atuação no mercado, ramo de atividade, produtos comercializados, quantidade de empregados, faturamento médio e estilo de gerenciamento).

O segundo grupo foi subdividido em quatro partes. As três primeiras foram dedicadas às variáveis: gestão de custos e formação do preço de venda, gestão de caixa e gestão de risco operacional, buscando identificar se os respondentes conheciam adequadamente as variáveis estudadas, qual o grau de importância atribuída a elas. E na quarta parte, abordou-se a utilização destas variáveis no processo de tomada de decisão.

Os dados coletados em campo foram tratados e analisados com o auxílio do SPSS versão 20.0. A princípio, foi realizada a análise descritiva dos dados e posteriormente fez-se uso da análise inferencial por meio dos testes de hipóteses Qui- 
Gestão de custos e formação de preço de venda, gestão de caixa e gestão de riscos: um estudo exploratório no arranjo produtivo local gesseiro do estado de Pernambuco Lucivaldo Lourenço da Silva Filho, Umbelina Cravo Teixeira Lagioia, João Gabriel Nascimento de Araújo, Juliana Gonçalves de Araujo, Francisco de Assis Carlos Filho

quadrado e teste exato de Fisher, utilizados no intuito de verificar a existência de associação entre as variáveis estudadas.

\section{ANÁLISE DOS DADOS}

\subsection{Análise dos Dados Socioeconômicos}

\subsubsection{Perfil dos entrevistados}

Foram entrevistados os proprietários, sócios, gerentes ou assistentes dos proprietários. A maior parte da amostra foi composta por gerentes $(54,72 \%)$, seguido dos proprietários e assistentes dos proprietários $(35,85 \%$ e $9,43 \%$ da amostra, respectivamente).

Foi verificado também qual o grau de instrução dos entrevistados, sendo identificado que dos 19 proprietários, 11 detêm o ensino médio e 8 a formação em curso superior. Dos 29 gerentes, 12 possuem o ensino médio, 17 possuem formação em curso superior, nos quais, apenas 1 possui além da graduação uma pós-graduação. Dos 5 assistentes, 2 deles possuem o ensino médio, e 3 possuem um curso superior, sendo que 1 destes possui uma pós-graduação.

A partir dos dados encontrados, percebeu-se que mais de $50 \%$ dos entrevistados possuem formação superior de natureza diversa. Os dados evidenciam que dentre os cursos mais citados, o de Ciências Biológicas prevaleceu dentre os demais (15\%), seguido por Ciências Contábeis e Letras (14\%). Outros cursos, que foram citados apenas uma vez pelos respondentes, representam $32 \%$ da amostra.

Perfil das Empresas

Das empresas estudadas, 47,17\% (25 empresas) já estão consolidadas no mercado, pois possuem mais de 5 anos de atuação no polo gesseiro. Por outro lado $30,19 \%$ (16 empresas) possuem de 2 a 5 anos; e 22,64\% (12 empresas) possuem até 2 anos.

Em relação aos produtos comercializados, verificou-se que a maioria das empresas pesquisadas 50,94\% (27 empresas) trabalha apenas com a calcinação, 
Gestão de custos e formação de preço de venda, gestão de caixa e gestão de riscos: um estudo exploratório no arranjo produtivo local gesseiro do estado de Pernambuco Lucivaldo Lourenço da Silva Filho, Umbelina Cravo Teixeira Lagioia, João Gabriel Nascimento de Araújo, Juliana Gonçalves de Araujo, Francisco de Assis Carlos Filho

enquanto 15,09\% (8 empresas) vendem o gesso em forma de pré-moldado, 28,30\% (15 empresas) vão desde a calcinação até a fabricação de pré-moldados, 3,77\% (2 empresas) exploram apenas a mineração e apenas 1,89\% (1 empresa) produz gessos especiais.

Em relação à quantidade de funcionários, optou-se pela classificação oferecida pelo Instituto Brasileiro de Geografia e Estatística (IBGE), a qual agrupa as empresas de acordo com o critério do número de funcionários. A partir desse critério, foi identificado que apenas 1 empresa é considerada empresa de médio porte, o que revela uma predominância no estudo de empresas Micro 52,83\% (28 empresas) e de pequeno porte $45,28 \%$ (24 empresas).

Também foi analisado o faturamento anual das empresas pesquisadas. Neste tópico a categorização das faixas de faturamento foi embasada na Lei Complementar 123/06, que trata do Regime Tributário do Simples Nacional. Diante do critério utilizado, constatou-se que das 53 empresas estudadas, apenas 7 (13,21\% da amostra) são empresas de médio a grande porte, enquanto 12 empresas (22,64\%) são Microempresas. A maioria da amostra estudada, representada por 34 empresas (64,15\%), são Empresas de Pequeno Porte. Esse resultado enfatiza a predominância na amostra desse estudo de Microempresas (ME) e Empresas de Pequeno Porte (EPP) as quais representam $86,79 \%$ da amostra.

\subsubsection{Perfil da Gestão da Empresa}

Com o objetivo de verificar como estas empresas tratam os seus dados patrimoniais, foi verificado se a Contabilidade delas é realizada internamente ou se é terceirizada por escritórios de contabilidade. Foi constatado que a grande maioria delas $(92,5 \%)$ contrata escritórios para o atendimento das suas obrigações legais e para o atendimento de suas necessidades internas.

Foi verificado ainda que não existe relação entre o porte da empresa e a decisão de se terceirizar os serviços de contabilidade. Das 4 empresas que afirmaram ter um departamento de Contabilidade, 2 delas faturam entre $R \$ 360.000,00$ e $R \$$ 
Gestão de custos e formação de preço de venda, gestão de caixa e gestão de riscos: um estudo exploratório no arranjo produtivo local gesseiro do estado de Pernambuco Lucivaldo Lourenço da Silva Filho, Umbelina Cravo Teixeira Lagioia, João Gabriel Nascimento de Araújo, Juliana Gonçalves de Araujo, Francisco de Assis Carlos Filho

3.600.000,00 por ano, e as outras 2 detém um faturamento acima $R \$ 3.600 .000,00$. Por outro lado, das 49 empresas restantes, 12 faturam abaixo de $R \$ 360.000,00$ ano, 32 faturam entre $R \$ 360.000,00$ e $R \$ 3.600 .000,00$ por ano, e 5 acima de $R \$ 3.600 .000$.

Já com relação ao modelo de gestão da amostra estudada, $69,81 \%$ dos respondentes relataram que, na maioria das vezes, as decisões são delegadas para os funcionários, enquanto $30,19 \%$ concentram as decisões. Este resultado evidencia uma predominância de gestões menos centralizadoras, o que permite uma maior participação dos colaboradores da empresa.

Com relação ao processo de tomada de decisão, foi questionado junto aos pesquisados como normalmente são tomadas as decisões na empresa. Os resultados demonstram que em $83,02 \%$ das empresas pesquisadas as decisões são baseadas tanto em fatores intuitivos quanto em relatórios e indicadores gerenciais, seguido por $15,09 \%$ que baseiam suas decisões exclusivamente em suas intuições, e apenas $1,89 \%$ das empresas escolheram a opção de utilizar os relatórios e indicadores gerenciais, e a partir desses dados escolherem a melhor opção.

\subsection{Análise das Variáveis Estudadas}

\subsubsection{Gestão de Custos e Formação do Preço de Venda}

No intuito de se verificar o entendimento sobre custos por parte dos gestores das empresas que compõem o APL gesseiro foram expostos os tipos de gastos mais frequentes em seus empreendimentos para que eles identificassem, dentre eles, o que seria custo.

Diante das opções disponibilizadas, os entrevistados declararam entender custo da seguinte maneira: 
Gestão de custos e formação de preço de venda, gestão de caixa e gestão de riscos: um estudo exploratório no arranjo produtivo local gesseiro do estado de Pernambuco Lucivaldo Lourenço da Silva Filho, Umbelina Cravo Teixeira Lagioia, João Gabriel Nascimento de Araújo, Juliana Gonçalves de Araujo, Francisco de Assis Carlos Filho

Tabela 1 - Entendimento de Custo

\begin{tabular}{|c|c|c|}
\hline Como os entrevistados entendem Custo & Frequência & $\%$ \\
\hline Gastos com administração da empresa & 1 & 2 \\
\hline Gastos com o processo produtivo & 12 & 23 \\
\hline Gastos administrativos e com o processo produtivo & 39 & 74 \\
\hline $\begin{array}{c}\text { Gastos administrativos; Processo produtivo; Aquisição de mercadoria; } \\
\text { e Prestação de serviço }\end{array}$ & 1 & 2 \\
\hline
\end{tabular}

Para um melhor entendimento desse tópico ressalta-se Martins (2008, p.25), o qual afirma que Custo é "Gasto relativo a bem ou serviço utilizado na produção de outros bens e serviços", enquanto Despesa é "Bem ou serviço consumido direta ou indiretamente para a obtenção de receitas".

Como todas as empresas estudadas são indústrias, os resultados encontrados evidenciam que a maioria dos entrevistados $(77,36 \%)$ confunde os conceitos de Custos e Despesas, pois, apenas $22,64 \%$ deles entendem que Custo seria apenas o gasto com o processo produtivo.

Em relação à importância atribuída às informações de custos na gestão das empresas pesquisadas, destaca-se o alto grau de importância dada às informações de custo pelos entrevistados $(75,47 \%$ da amostra). Verificou-se ainda que $22,64 \%$ dos entrevistados a considerarem como importante, e apenas 1,89\% consideraram como pouco importante.

Esse comportamento identificado nos respondentes das empresas em relação ao nível de importância atribuído às informações de custo, também foi verificado no processo de formação do preço de venda na gestão das empresas. Neste caso, verificou-se que $77,36 \%$ dos respondentes das empresas revelam considerar esse processo como "muito importante", enquanto que $22,64 \%$ consideram-no "importante", não havendo aqueles que consideram o referido processo com pouca ou sem importância. 
Gestão de custos e formação de preço de venda, gestão de caixa e gestão de riscos: um estudo exploratório no arranjo produtivo local gesseiro do estado de Pernambuco Lucivaldo Lourenço da Silva Filho, Umbelina Cravo Teixeira Lagioia, João Gabriel Nascimento de Araújo, Juliana Gonçalves de Araujo, Francisco de Assis Carlos Filho

Tabela 2 - Grau de importância atribuído a gestão de custos e formação de preço de venda

\begin{tabular}{|c|c|c|}
\hline $\begin{array}{c}\text { Grau de importância das informações de custos na } \\
\text { gestão da empresa }\end{array}$ & Frequência & $\%$ \\
\hline Pouco importante & 1 & 1,89 \\
\hline Importante & 12 & 22,64 \\
\hline Muito importante & 40 & 75,47 \\
\hline $\begin{array}{c}\text { Grau de Importância do processo de formação do Preço } \\
\text { de Venda }\end{array}$ & Frequência & $\%$ \\
\hline Importante & 12 & 22,64 \\
\hline Muito importante & 41 & 77,36 \\
\hline
\end{tabular}

Os dados desta pesquisa também revelaram que a maioria das empresas estudadas $(92,45 \%)$ realiza a análise de seus gastos mais relevantes e acompanha sua evolução, demonstrando que as empresas pesquisadas detêm a postura citada anteriormente, e que nenhuma empresa pesquisada não verifica quais são os seus custos relevantes. Contudo, salienta-se que $7,55 \%$ dos entrevistados verificam quais são seus custos relevantes, mas não utilizam essa informação na gestão da empresa.

Diante da constatação de que a maioria das empresas realiza o acompanhamento dos seus custos relevantes, foi questionado aos entrevistados se o controle seria feito manualmente ou por meio de algum sistema específico. Analisandose as respostas, verificou-se que $69,81 \%$ delas fazem o controle por meio de planilhas eletrônicas, através do sistema Microsoft Excel, enquanto 30,19\% detêm sistemas operacionais que possuem a ferramenta de controle de custo.

Alguns dos motivos citados pelos entrevistados para justificarem a não utilização de um sistema mais específico de custos foram os seguintes:

- O controle via planilha de Excel atende a necessidade;

- A empresa é pequena e, por enquanto, não precisa de um sistema;

- Um sistema com essa ferramenta é caro.

- O controle via planilha de Excel atende a necessidade, mas um sistema específico de Custo seria melhor para a organização. 
Gestão de custos e formação de preço de venda, gestão de caixa e gestão de riscos: um estudo exploratório no arranjo produtivo local gesseiro do estado de Pernambuco Lucivaldo Lourenço da Silva Filho, Umbelina Cravo Teixeira Lagioia, João Gabriel Nascimento de Araújo, Juliana Gonçalves de Araujo, Francisco de Assis Carlos Filho

Posteriormente, foi verificado qual é o método de custeio que as empresas utilizavam para mensuração do custo dos seus produtos. Observou-se que 3 empresas (5,66\%) declararam utilizar o Método de Custeio Variável, enquanto 19 (35,85\%) utilizam o Custeio por Absorção. Encontrou-se também que 30 (56,60\%) das empresas afirmaram utilizar o "Método da soma dos custos do mês", e uma empresa especificou que a forma de apurar custos é a "Busca pelo ponto de equilíbrio". Estes dois últimos não são métodos de apuração de custos previstos na literatura, contudo, optou-se neste trabalho por preservar a opinião dos respondentes.

Outro questionamento decorrente foi: qual seria a utilidade das informações de custos para as empresas entrevistadas? Nesse ínterim, verificou-se das 53 empresas entrevistadas apenas uma declarou não utilizar as informações de custos em suas atividades empresariais.

Entretanto, salienta-se que o proprietário dessa empresa afirmou que não utiliza efetivamente as informações de custo da empresa por considerar que a produção da empresa é pequena e não há necessidade desta efetiva utilização, e que esse é um comportamento temporário, e que futuramente ele pretende utilizar.

As outras 52 empresas declararam utilizar as informações em suas atividades empresariais, nas quais, 17 utilizam para atendimento da legislação fiscal, 47 usam no processo de formação do preço de venda e 34 na negociação com fornecedores e/ou clientes.

Tabela 3 - Utilidade das informações de custos nas atividades empresariais

\begin{tabular}{|c|c|c|c|c|c|c|}
\hline \multirow{2}{*}{} & \multicolumn{2}{|c|}{$\begin{array}{c}\text { Para atendimento da } \\
\text { legislação fiscal }\end{array}$} & \multicolumn{2}{c|}{$\begin{array}{c}\text { Para formação do } \\
\text { preço de venda }\end{array}$} & \multicolumn{2}{c|}{$\begin{array}{c}\text { Para negociação com } \\
\text { Fornecedores elou Clientes }\end{array}$} \\
\cline { 2 - 7 } & Frequência & $\%$ & Frequência & $\%$ & Frequência & $\%$ \\
\hline Sim & 17 & 32,08 & 47 & 88,68 & 34 & 64,15 \\
\hline Não & 36 & 67,92 & 6 & 11,32 & 19 & 35,85 \\
\hline
\end{tabular}


Gestão de custos e formação de preço de venda, gestão de caixa e gestão de riscos: um estudo exploratório no arranjo produtivo local gesseiro do estado de Pernambuco Lucivaldo Lourenço da Silva Filho, Umbelina Cravo Teixeira Lagioia, João Gabriel Nascimento de Araújo, Juliana Gonçalves de Araujo, Francisco de Assis Carlos Filho

Além destas opções fornecidas diretamente no questionário utilizado nesta pesquisa, 11 entrevistados também informaram que usam as informações de custos com outras finalidades, quais sejam: controle de gastos,identificar possíveis gargalos e controle dos custos e contribuem para a sobrevivência no mercado.

Os resultados apresentados revelam que praticamente todas as empresas utilizam as informações de custo em suas atividades empresariais, das quais $88,68 \%$ enfatizaram utilizar diretamente essas informações no processo de formação do preço de venda.

Para constatar os critérios utilizados para definição do preço de venda das empresas, foram disponibilizadas as seguintes alternativas: Análise do custo acrescido da margem de lucro desejada; Considera o preço de mercado; Considera as informações de custos, margem de lucro e preço praticado no mercado; Negocia o preço caso a caso; Outros, especificar.

A partir dos resultados da pesquisa, observou-se que apenas o critério de "realizar uma análise dos custos e acrescentar a margem de lucro desejada" não foi utilizado conjuntamente com nenhum outro critério disponibilizado as empresas entrevistadas, e apenas uma empresa declarou utilizar esta política de formação de preço de venda.

O critério de formação de preço que mais empresas declararam utilizar foi o que considera o custo, margem de lucro e o preço praticado no mercado, critério no qual 43 empresas afirmaram utilizar. Contudo, salienta-se que destas, 26 empresas relataram que além de usar essa política de preço, também "negociam o preço caso a caso".

Verificou-se ainda que 31 empresas afirmaram negociar o seu preço de venda caso a caso. Essa atitude não revela que as empresas irão mudar o seu preço a cada venda realizada, mas que em determinadas situações do negócio eles chegam a negociar os seus preços de venda.

Essa assertiva se confirma quando observado que destas 31 empresas, 3 delas também afirmaram que "consideram o preço de mercado" e 26 "Consideram o custo, 
Gestão de custos e formação de preço de venda, gestão de caixa e gestão de riscos: um estudo exploratório no arranjo produtivo local gesseiro do estado de Pernambuco Lucivaldo Lourenço da Silva Filho, Umbelina Cravo Teixeira Lagioia, João Gabriel Nascimento de Araújo, Juliana Gonçalves de Araujo, Francisco de Assis Carlos Filho

margem de lucro e preço praticado no mercado", restando apenas 4 que negociam o seu preço venda a venda.

Outra política de preço verificada foi a que considera o preço de mercado. Essa opção foi escolhida por 7 empresas, porém destas, 3 empresas afirmaram utilizar essa política em conjunto com a de negociar o preço de venda caso a caso.

Com relação ao preço de venda, também foi observado qual o posicionamento das empresas estudadas com relação às vendas a prazo. Neste sentido, foi verificado que 4 empresas alegaram não realizar vendas a prazo. Neste caso especificamente, elas informaram que a venda é realizada, mas que o produto só é liberado para entrega após a realização do pagamento.

Outras 10 empresas informaram que vendem a prazo, mas sem a incidência de encargos financeiros. Desta maneira, elas vendem a prazo utilizando o mesmo preço da venda a vista. Entretanto, a maioria das empresas estudadas vende a prazo (43 empresas), sendo que 37 incluem encargos financeiros.

Conforme já mencionado na Tabela $16,88,68 \%$ das empresas utilizam as informações de custo para a formação do preço de venda, e, também foi verificado, se esse comportamento se repete quando perguntado se a gestão de custo é utilizada em seu processo decisório.

Em seguida, observou-se a finalidade que as empresas pesquisadas utilizavam a gestão de custo, no qual verificou-se que de 49 empresas que declararam utilizar essa ferramenta, 55,10\% utilizam para análise de desempenho e para obter uma vantagem competitiva, e $75,51 \%$ para obter um maior controle organizacional. 
Gestão de custos e formação de preço de venda, gestão de caixa e gestão de riscos: um estudo exploratório no arranjo produtivo local gesseiro do estado de Pernambuco Lucivaldo Lourenço da Silva Filho, Umbelina Cravo Teixeira Lagioia, João Gabriel Nascimento de Araújo, Juliana Gonçalves de Araujo, Francisco de Assis Carlos Filho

Tabela 4 - Finalidade de utilização da Gestão de Custo

\begin{tabular}{|c|c|c|c|c|c|c|}
\hline \multirow{3}{*}{$\begin{array}{l}\text { Utiliza a } \\
\text { gestão de } \\
\text { custo no } \\
\text { processo } \\
\text { decisório }\end{array}$} & \multicolumn{6}{|c|}{ FINALIDADE } \\
\hline & \multicolumn{2}{|c|}{$\begin{array}{c}\text { Análise de } \\
\text { desempenho }\end{array}$} & \multicolumn{2}{|c|}{$\begin{array}{l}\text { Obter vantagem } \\
\text { competitiva }\end{array}$} & \multicolumn{2}{|c|}{$\begin{array}{c}\text { Controle } \\
\text { Organizacional }\end{array}$} \\
\hline & Sim & Não & Sim & Não & Sim & Não \\
\hline Sim & $\begin{array}{c}27 \\
(55,10 \%) \\
\end{array}$ & $\begin{array}{c}22 \\
(44,90 \%) \\
\end{array}$ & $\begin{array}{c}27 \\
(55,10 \%)\end{array}$ & $\begin{array}{c}22 \\
(44,90 \%)\end{array}$ & $\begin{array}{c}37 \\
(75,51 \%)\end{array}$ & $\begin{array}{c}12 \\
(24,49 \%) \\
\end{array}$ \\
\hline Não & $\begin{array}{c}1 \\
(25,0 \%)\end{array}$ & $\begin{array}{c}3 \\
(75,0 \%)\end{array}$ & $0(0,0 \%)$ & $\begin{array}{c}4 \\
(100,0 \%)\end{array}$ & $\begin{array}{c}2 \\
(50,0 \%)\end{array}$ & $\begin{array}{c}2 \\
(50,0 \%)\end{array}$ \\
\hline
\end{tabular}

Já em relação à utilização da formação do preço de venda no processo decisório $88,68 \%$ (47) das empresas declararam utilizar essa variável. Esse resultado demonstra que a maioria das empresas pesquisadas utiliza a variável "formação do preço de venda" objeto de estudo deste trabalho, no entanto, esta variável não alcançou o mesmo nível de utilização da variável gestão de custo.

\subsubsection{Gestão de Caixa}

No intuito de se verificar o conhecimento relacionado à Gestão de Caixa dos gestores das empresas que compõem o APL gesseiro, foi observado o entendimento de disponibilidade de caixa dos entrevistados.

Em relação ao entendimento de disponibilidade de caixa, Comelli (2009) relata que devem ser considerados como disponibilidades os valores em caixa, os depósitos bancários à vista, numerários em trânsito e aplicações de liquidez imediata.

Deste modo, em conformidade com o entendimento anteriormente citado, inferese que apenas $15,09 \%$ dos respondentes detém o entendimento correto do que seriam disponibilidades de caixa. $\mathrm{O}$ item em que aparentemente mais levou os participantes da pesquisa a confundir esse conceito foi o do contas a receber, pois $18,87 \%$ deles consideraram que este integra o conceito de disponibilidades de caixa. 
Gestão de custos e formação de preço de venda, gestão de caixa e gestão de riscos: um estudo exploratório no arranjo produtivo local gesseiro do estado de Pernambuco Lucivaldo Lourenço da Silva Filho, Umbelina Cravo Teixeira Lagioia, João Gabriel Nascimento de Araújo, Juliana Gonçalves de Araujo, Francisco de Assis Carlos Filho

Tabela 5 - Entendimento de Disponibilidade de caixa

\begin{tabular}{|c|c|c|}
\hline $\begin{array}{c}\text { Entendimento dos respondentes com relação à disponibilidade } \\
\text { de caixa }\end{array}$ & Frequência & $\%$ \\
\hline Caixa, Bancos e aplicações financeiras de liquidez imediata & 8 & 15,09 \\
\hline Caixa, Bancos, aplicações financeiras e imobilizado & 2 & 3,77 \\
\hline Caixa e bancos & 33 & 62,26 \\
\hline Caixa, Bancos, aplicações financeiras e valores a receber & 10 & 18,87 \\
\hline
\end{tabular}

Também salienta-se que a opção que foi a escolhida pela maioria dos entrevistados $(62,26 \%)$, a de entender como a soma do caixa da empresa mais os valores disponíveis em bancos, é uma opção que para ser compreendida como correta falta apenas considerar as aplicações financeiras de liquidez imediata.

Contudo, mesmo a maioria dos respondentes não entendendo adequadamente o conceito de disponibilidade de caixa, a maioria (86,79\%) consideram as informações para gestão de caixa na administração da empresa como "muito importante", e 13,21\% afirmam que ela seja apenas importante. Salienta-se que nenhum dos respondentes considerou como sem ou pouco importante, evidenciando que $100 \%$ dos pesquisados classificam como importantes ou muito importantes.

No que se refere à utilização da gestão de caixa nas empresas do APL gesseiro estudadas, inicialmente foi verificado a frequência com que elas administram as suas disponibilidades de caixa, no qual foi observado que a maioria das empresas representadas por $92,45 \%$ das empresas entrevistadas realizam a administração diária das suas disponibilidades de caixa, enquanto $8 \%$ fazem semanalmente. Salienta-se que nenhuma empresa estudada realiza a administração em períodos superiores a uma semana.

Mesmo sendo observado que todas as empresas planejam os seus recebimentos e pagamentos, foi verificado se estas empresas acompanham a realização do planejado fluxo, nas quais $100 \%$ dos respondentes afirmaram que suas empresas realizam o efetivo acompanhamento do que foi planejado como recebível ou pagável. 
Gestão de custos e formação de preço de venda, gestão de caixa e gestão de riscos: um estudo exploratório no arranjo produtivo local gesseiro do estado de Pernambuco Lucivaldo Lourenço da Silva Filho, Umbelina Cravo Teixeira Lagioia, João Gabriel Nascimento de Araújo, Juliana Gonçalves de Araujo, Francisco de Assis Carlos Filho

Relacionado à gestão de caixa, foi verificado qual o tratamento adotado pelas empresas acerca das sobras de caixa, quando existentes.

Das opções disponibilizadas aos respondentes, a alternativa de aplicar esta sobra em algum tipo de investimento de ativo fixo foi a que obteve uma maior aceitação com 39,62\%, enquanto analisar a melhor opção a ser feita com a sobra de caixa foi a segunda alternativa com maior aceitação com 35,85\%. Verificou-se ainda que $26,42 \%$ mantém a disponibilidade em caixa, e 1,89\% aplicam esses recursos em investimentos financeiros.

Tabela 6 - Destinação das sobras de caixa

\begin{tabular}{|c|c|c|c|c|c|c|c|c|}
\hline & \multicolumn{2}{|c|}{ Mantém em caixa } & \multicolumn{2}{c|}{$\begin{array}{c}\text { Aplica em ativo } \\
\text { fixo }\end{array}$} & \multicolumn{2}{c|}{$\begin{array}{c}\text { Aplica em } \\
\text { Investimentos } \\
\text { financeiros }\end{array}$} & \multicolumn{2}{c|}{ Analisa a melhor opção } \\
\cline { 2 - 9 } & Frequência & $\%$ & Frequência & $\%$ & Frequência & $\%$ & Frequência & $\%$ \\
\hline Sim & 14 & 26,42 & 21 & 39,62 & 1 & 1,89 & 19 & 35,85 \\
\hline Não & 39 & 73,58 & 32 & 60,38 & 52 & 98,11 & 34 & 64,15 \\
\hline
\end{tabular}

O resultado verificado demonstra comportamentos adversos entre os respondentes das empresas estudadas, pois a maioria destas empresas representada por $67,93 \%$ não analisam a melhor opção a ser tomada com estes recursos disponíveis.

Outro resultado deste estudo é de que a maioria das empresas, representada por $92,45 \%$ delas, utilizam a variável "Gestão de Caixa", objeto de estudo deste trabalho em seu processo decisório.

Em seguida observou-se a finalidade com que as empresas pesquisadas utilizavam a gestão de custo, no qual verificou-se que das 49 que anteriormente declararam utilizar essa ferramenta, 53,06\% utilizam para análise de desempenho e para obter uma vantagem competitiva, e $73,47 \%$ para obter um maior controle organizacional. 
Gestão de custos e formação de preço de venda, gestão de caixa e gestão de riscos: um estudo exploratório no arranjo produtivo local gesseiro do estado de Pernambuco Lucivaldo Lourenço da Silva Filho, Umbelina Cravo Teixeira Lagioia, João Gabriel Nascimento de Araújo, Juliana Gonçalves de Araujo, Francisco de Assis Carlos Filho

Tabela 7 - Finalidade de utilização da Gestão de Caixa

\begin{tabular}{|c|c|c|c|c|c|c|}
\hline \multirow{3}{*}{$\begin{array}{l}\text { Utiliza a gestão de caixa no } \\
\text { processo decisório }\end{array}$} & \multicolumn{6}{|c|}{ FINALIDADE } \\
\hline & \multicolumn{2}{|c|}{$\begin{array}{c}\text { Análise de } \\
\text { desempenho }\end{array}$} & \multicolumn{2}{|c|}{$\begin{array}{l}\text { Obter vantagem } \\
\text { competitiva }\end{array}$} & \multicolumn{2}{|c|}{$\begin{array}{c}\text { Controle } \\
\text { Organizacional }\end{array}$} \\
\hline & Sim & Não & Sim & Não & Sim & Não \\
\hline Sim & $\begin{array}{c}26 \\
(53,06 \%)\end{array}$ & $\begin{array}{c}23 \\
(46,94 \%)\end{array}$ & $\begin{array}{c}26 \\
(53,06 \%)\end{array}$ & $\begin{array}{c}23 \\
(46,94 \%)\end{array}$ & $\begin{array}{c}36 \\
(73,47 \%)\end{array}$ & $\begin{array}{c}13 \\
(26,53 \%)\end{array}$ \\
\hline Não & $\begin{array}{c}2 \\
(50,0 \%)\end{array}$ & $\begin{array}{c}2 \\
(50,0 \%)\end{array}$ & $\begin{array}{c}1 \\
(25,0 \%)\end{array}$ & $\begin{array}{c}3 \\
(75,0 \%)\end{array}$ & $\begin{array}{c}3 \\
(75,0 \%)\end{array}$ & $\begin{array}{c}1 \\
(25,0 \%)\end{array}$ \\
\hline
\end{tabular}

Em relação à finalidade de utilização da gestão de caixa no processo decisório, os resultados encontrados assemelham-se aos encontrados na gestão de custo, a única divergência encontra-se na finalidade controle organizacional, que neste tópico de gestão de caixa, $73,47 \%$ declararam utilizar, enquanto para a gestão de custo o controle organizacional é uma finalidade utilizada por $75,51 \%$.

\subsubsection{Gestão do Risco Operacional}

No que se refere à Gestão do risco operacional, foi investigado se os pesquisados conhecem o Risco Operacional em conformidade com o concebido pelo Comitê da Basiléia (BIS, 2004) como o risco de perda resultante de processos internos inadequados ou falhos, pessoas e sistemas, ou eventos externos.

Deste modo, dentre os respondentes, foi considerado como quem entendem corretamente risco operacional aqueles que escolheram "exclusivamente" a opção "Riscos de perdas associadas a falhas nos processos internos, pessoas e sistemas, ou, ainda, a eventos externos", e aqueles que além desta opção, também escolheram a opção "Possibilidade de perdas resultantes de multas, penalidades ou indenizações".

Assim, apenas $30,19 \%$ (16) dos respondentes entenderam de forma adequada o conceito de risco operacional.

Diante os resultados da pesquisa, foi verificado que o erro mais comum dos respondentes foi o de escolher a opção que abordava o risco operacional em conjunto com a opção que abordava o risco de credito, seguido por aqueles que além de 
Gestão de custos e formação de preço de venda, gestão de caixa e gestão de riscos: um estudo exploratório no arranjo produtivo local gesseiro do estado de Pernambuco Lucivaldo Lourenço da Silva Filho, Umbelina Cravo Teixeira Lagioia, João Gabriel Nascimento de Araújo, Juliana Gonçalves de Araujo, Francisco de Assis Carlos Filho

escolher a opção que contempla o risco operacional também declararam que esse tipo de risco está associado à desvalorização de seu produto no mercado. Esses equívocos ocorreram respectivamente com $39,62 \%$, e $18,87 \%$ dos respondentes.

Conforme já apresentado anteriormente, a maioria dos respondentes $(69,81 \%)$ não entendem o risco operacional adequadamente, no entanto, eles atribuem um alto grau de importância a esta variável de pesquisa, pois, a gestão de risco operacional é tida para os pesquisados como Importante $(28,30 \%)$, ou muito importante $(71,70 \%)$, não havendo nenhum considerado como sem ou pouco importante.

No que se refere às fraudes internas, verificou-se que $90,57 \%$ das empresas monitoram a possibilidade erros, falhas ou fraudes dos funcionários.

Quanto às práticas empregatícias das empresas e da segurança no ambiente de trabalho, 96,23\% delas declararam atender aos padrões trabalhistas previstos em lei, já quanto à segurança do ambiente de trabalho $83,02 \%$ dos respondentes consideram que a atividade da empresa é insalubre e perigosa, contudo, 96,23\% disponibilizam equipamentos de proteção (E.P.I) para os seus funcionários.

Para a averiguação do controle dos danos nos ativos físicos, foi inicialmente verificado se a empresa possuem ativos fixos sujeito a danos, no qual, 96,23\% afirmaram deter esses ativos, das quais 94,34\% das empresas realizam o monitoramento dos seus ativos, assim como, 100\% delas declararam realizarem revisão periódica em suas instalações físicas, e para evitar as falhas de sistemas, $77,36 \%$ das empresas informaram que investem em tecnologia para a gestão da empresa.

Com relação aos processos, observou-se que $37,74 \%$ das empresas formalizam as rotinas operacionais e administrativas com o fim de facilitar o controle das rotinas, $58,49 \%$ faz uso de formulário ou relatório de revisão das rotinas operacionais e administrativas, assim como, $62,26 \%$ se utilizam de mecanismos de identificação e análise dos riscos inerentes às operações da empresa.

E no âmbito das situações relacionadas aos clientes, produtos e as práticas de negócio, verificou-se que $83,02 \%$ afirmam controlar possíveis insuficiências de 
Gestão de custos e formação de preço de venda, gestão de caixa e gestão de riscos: um estudo exploratório no arranjo produtivo local gesseiro do estado de Pernambuco Lucivaldo Lourenço da Silva Filho, Umbelina Cravo Teixeira Lagioia, João Gabriel Nascimento de Araújo, Juliana Gonçalves de Araujo, Francisco de Assis Carlos Filho

infraestrutura, recursos humanos e materiais, enquanto, $100 \%$ das empresas defenderam adquirir matérias-primas que atendem a atividade operacional, 88,68\% previnem perdas com seus fornecedores, e também previnem a ocorrência de danos aos produtos, durante o desenvolvimento das atividades, $92,45 \%$ realizam 0 monitoramento de falhas não intencionais em seus produtos, assim como, 94,34\% declararam oferecer produtos e serviços adequados e devidamente formalizados, e também fornecem produtos suficientes para atender a demanda externa, contudo, apenas $41,51 \%$ elaboram estratégias para o transporte dos seus produtos desde a origem até o destino.

Também foi verificado se teria algum motivo que levaria a empresa a não realizar a gestão de risco operacional, no entanto, nenhum respondente se posicionou, deste modo, a partir dos dados apresentados constata-se que as empresas estudadas utilizam a gestão de risco operacional na gestão de suas respectivas empresas, e neste contexto, também foi verificado se estas empresas levam em consideração a gestão do risco operacional em seu processo decisório.

Esse resultado demonstra que a maioria das empresas, representada por $86,79 \%$, utilizam a variável "Gestão de risco operacional", objeto de estudo deste trabalho em seu processo decisório.

Em seguida observou-se a finalidade com que as empresas pesquisadas utilizavam a gestão de risco operacional, no qual verificou-se que das 46 que anteriormente declararam utilizar essa variável, 50,0\% utilizam para análise de desempenho, 58,47\% para obter uma vantagem competitiva, enquanto, $71,74 \%$ utilizam para obter um maior controle organizacional.

Deste modo, infere-se que a maioria das empresas utiliza a gestão de risco operacional em sua gestão e no seu respectivo processo decisório, tendo como principal finalidade o controle organizacional. 
Gestão de custos e formação de preço de venda, gestão de caixa e gestão de riscos: um estudo exploratório no arranjo produtivo local gesseiro do estado de Pernambuco Lucivaldo Lourenço da Silva Filho, Umbelina Cravo Teixeira Lagioia, João Gabriel Nascimento de Araújo, Juliana Gonçalves de Araujo, Francisco de Assis Carlos Filho

\subsection{Análise Inferencial das Variáveis}

\subsubsection{Gestão de custo e formação do preço de venda}

Diante a realização da tabulação cruzada entre o conhecimento do conceito de custo e o nível de importância atribuído às informações de custo e as informações sobre o processo de formação de preço na gestão da empresa (Tabela 8), verificou-se que a maioria daqueles que não conhecem adequadamente o conceito de custo $(77,36 \%)$ considera as informações de custo muito importante $(73,2 \%)$. Contudo, foi verificado por meio do teste Exato de Fischer que a atribuição de importância à informação de custos na gestão, independe do nível de conhecimento dos entrevistados sobre este assunto ( $p$ valor $>5 \%$ ).

Porém, na relação entre o conhecimento de custo e o nível de importância das informações sobre o processo de formação de preço na gestão da empresa, observouse que daqueles que não conhecem adequadamente o conceito de custo $(77,36 \%$ da amostra), 70,7\% consideram-no muito importante para a gestão o processo de formação de preço, no entanto, diferentemente do resultado anterior, por meio do resultado do teste do exato de Fisher, constatou-se que esta relação foi estatisticamente significativa ( $p$ valor $=0,048$ ). 
Gestão de custos e formação de preço de venda, gestão de caixa e gestão de riscos: um estudo exploratório no arranjo produtivo local gesseiro do estado de Pernambuco Lucivaldo Lourenço da Silva Filho, Umbelina Cravo Teixeira Lagioia, João Gabriel Nascimento de Araújo, Juliana Gonçalves de Araujo, Francisco de Assis Carlos Filho

Tabela 8 - Conhecimento x Nível de importância atribuído as informações de custo e as informações sobre o processo de formação de preço na gestão da empresa

\begin{tabular}{|c|c|c|c|c|c|}
\hline \multirow{2}{*}{ Conhece o conceito de Custo } & \multicolumn{4}{|c|}{$\begin{array}{l}\text { Nível de importância atribuída às } \\
\text { informações de custo na gestão da } \\
\text { empresa }\end{array}$} & \multirow{2}{*}{$p$-valor } \\
\hline & $\begin{array}{c}\text { Pouco } \\
\text { Importante }\end{array}$ & \multicolumn{2}{|c|}{ Importante } & $\begin{array}{c}\text { Muito } \\
\text { Importante }\end{array}$ & \\
\hline Conhece & $0(0,00 \%)$ & \multicolumn{2}{|c|}{$2(16,7 \%)$} & $10(83,3 \%)$ & \multirow{2}{*}{0,775} \\
\hline Não Conhece & $1(2,4 \%)$ & 10 & ,4\%) & $30(73,2 \%)$ & \\
\hline \multirow[t]{2}{*}{ Conhece o conceito de Custo } & \multicolumn{4}{|c|}{$\begin{array}{c}\text { Nível de importância atribuída às } \\
\text { informações sobre o processo de } \\
\text { formação do preço na gestão de sua } \\
\text { empresa. }\end{array}$} & \multirow[t]{2}{*}{$p$-valor } \\
\hline & \multicolumn{2}{|c|}{ Importante } & \multicolumn{2}{|c|}{ Muito Importante } & \\
\hline Conhece & \multicolumn{2}{|c|}{$0(0,00 \%)$} & \multicolumn{2}{|c|}{$12(100 \%)$} & \multirow{2}{*}{0,048} \\
\hline Não Conhece & \multicolumn{2}{|c|}{$12(29,3 \%)$} & \multicolumn{2}{|c|}{$29(70,7 \%)$} & \\
\hline
\end{tabular}

Em relação à associação entre conhecimento e a realização da verificação e acompanhamento dos custos relevantes na gestão da empresa, foi verificado que parte significativa da amostra estudada não conhecerem adequadamente o conceito de custo (77,36\%), no entanto, destes, 90,2\% declararam ter a prática de verificar e acompanhar quais são os seus custos relevantes meio a gestão da empresa. Também conforme a Tabela 9, dos $77,36 \%$ citados anteriormente, 92,5\% também declararam utilizar a gestão de custos em seus respectivos processos decisórios.

Através da análise dessa Tabela cruzada (Tabela 9) verifica-se que embora a maioria dos pesquisados não conhecerem adequadamente o conceito de custo, elesdetém a prática de verificar e acompanhar seus custos relevantes, e também utilizam a gestão de custo em seu processo decisório, no entanto, estas associações realizadas não apresentaram resultados estaticamente significativos. 
Gestão de custos e formação de preço de venda, gestão de caixa e gestão de riscos: um estudo exploratório no arranjo produtivo local gesseiro do estado de Pernambuco Lucivaldo Lourenço da Silva Filho, Umbelina Cravo Teixeira Lagioia, João Gabriel Nascimento de Araújo, Juliana Gonçalves de Araujo, Francisco de Assis Carlos Filho

Tabela 9 - Conhecimento x Verificação dos Custos relevantes e Utilização da Gestão de Custos no Processo decisório

\begin{tabular}{|c|c|c|c|c|}
\hline \multirow{2}{*}{$\begin{array}{c}\text { Conhece o conceito } \\
\text { de Custo }\end{array}$} & $\begin{array}{c}\text { Verifica e acompanha os custos } \\
\text { relevantes na gestão da } \\
\text { empresa }\end{array}$ & \multicolumn{2}{|c|}{$\begin{array}{c}\text { Utiliza a Gestão de Custo no } \\
\text { processo decisório }\end{array}$} \\
\cline { 2 - 5 } & Sim & Não & Sim & Não \\
\hline Conhece & $12(100,0 \%)$ & $0(100,0 \%)$ & $\begin{array}{c}11 \\
(91,7 \%)\end{array}$ & $1(8,3 \%)$ \\
\hline Não Conhece & $37(90,2 \%)$ & $4(9,8 \%)$ & $\begin{array}{c}38 \\
(92,5 \%)\end{array}$ & $3(7,3 \%)$ \\
\hline$p$-valor & \multicolumn{2}{|c|}{0,563} & & 1,00 \\
\hline
\end{tabular}

Em outro aspecto observou-se que daqueles entrevistados que consideraram as informações de custo na gestão do negócio como muito importante $(75,47 \%), 95 \%$ deles também utilizam a gestão de custo em seu respectivo processo decisório, no entanto, considerando-se o nível de significância de 5\%, esta não é uma associação estatisticamente significativa, pois o $p$-valor encontrado foi de 0,073 .

Comportamento semelhante foi identificado quando realizado o cruzamento entre o nível de importância das informações de custos na gestão do negócio e a utilização da formação de preço no processo decisório. Nesta associação verificou-se que 92,5\% daqueles que consideraram como muito importante as informações de custo, também levam em consideração o processo de formação de preço de venda em seu processo decisório, e assim, tal como verificado no resultado encontrado em relação à utilização da gestão de custo, esta relação também não é estatisticamente significativa ( $p$ valor > $5 \%)$.

\subsubsection{Gestão de Caixa}

O cruzamento realizado que obteve significância estatística para essa variável foi relacionado a associação entre as frequências de administração das disponibilidades de caixa e o planejamento de recebimentos e pagamentos. Neste contexto, verificou-se conforme a Tabela 10, que existe uma relação estatisticamente positiva entre estas duas variáveis ( $p$ valor $=0,001$ ). 
Gestão de custos e formação de preço de venda, gestão de caixa e gestão de riscos: um estudo exploratório no arranjo produtivo local gesseiro do estado de Pernambuco Lucivaldo Lourenço da Silva Filho, Umbelina Cravo Teixeira Lagioia, João Gabriel Nascimento de Araújo, Juliana Gonçalves de Araujo, Francisco de Assis Carlos Filho

Tabela 10 - Frequência de administração das disponibilidades de caixa x Frequência de administração das disponibilidades de caixa

\begin{tabular}{|c|c|c|c|c|}
\hline \multirow{2}{*}{$\begin{array}{c}\text { Frequência que a empresa } \\
\text { administra as suas } \\
\text { disponibilidades de caixa }\end{array}$} & \multicolumn{3}{|c|}{$\begin{array}{c}\text { Frequência com que a empresa } \\
\text { plane fa o fluxo de caixa de } \\
\text { recebimentos e pagamentos }\end{array}$} & \multirow{2}{*}{$\boldsymbol{p}$-valor } \\
\cline { 2 - 4 } & Diária & Semanal & Quinzenal & \\
\hline Diária & $47(95,9 \%)$ & $2(4,1 \%)$ & $0(0,0 \%)$ & \multirow{2}{*}{$\mathbf{0 , 0 0 1}$} \\
\hline Semanal & $1(25,0 \%)$ & $1(25,0 \%)$ & $2(50,0 \%)$ & \\
\hline
\end{tabular}

Desta maneira, infere-se que as empresas pesquisadas, quando administram as suas disponibilidades de caixa diariamente tendem a também realizar o planejamento dos fluxos de caixa de recebimentos e pagamentos diariamente.

\subsubsection{Gestão de Risco Operacional}

Quanto às relações testadas sobre as questões de risco foram encontradas algumas estatisticamente significantes.

Foi verificada a relação existente entre a gestão do risco operacional com a utilização de alguns eventos relacionados aos riscos inerentes a fraudes internas, práticas empregatícias e segurança no ambiente de trabalho, possíveis danos aos ativos físicos da empresa, falhas de sistemas, processos operacionais da empresa, e seus produtos. Os dados encontrados estão dispostos na Tabela 11. 
Gestão de custos e formação de preço de venda, gestão de caixa e gestão de riscos: um estudo exploratório no arranjo produtivo local gesseiro do estado de Pernambuco Lucivaldo Lourenço da Silva Filho, Umbelina Cravo Teixeira Lagioia, João Gabriel Nascimento de Araújo, Juliana Gonçalves de Araujo, Francisco de Assis Carlos Filho

Tabela 11 - Nível de importância da gestão de risco operacional x Eventos de riscos operacionais

\begin{tabular}{|c|c|c|c|c|}
\hline \multirow{4}{*}{$\begin{array}{l}\text { Riscos inerentes aos } \\
\text { processos } \\
\text { operacionais da } \\
\text { empresa }\end{array}$} & \multirow{2}{*}{$\begin{array}{l}\text { Utiliza a gestão de } \\
\text { risco operacional } \\
\text { no processo } \\
\text { decisório }\end{array}$} & \multicolumn{2}{|c|}{$\begin{array}{c}\text { Utilizam mecanismos de } \\
\text { identificação e análise dos } \\
\text { riscos inerentes às operações da } \\
\text { empresa }\end{array}$} & \multirow[t]{2}{*}{$p$-valor } \\
\hline & & Sim & Não & \\
\hline & Sim & $32(69,6 \%)$ & $14(30,4 \%)$ & \multirow{2}{*}{0,009} \\
\hline & Não & $1(14,3 \%)$ & $6(85,7 \%)$ & \\
\hline \multirow{8}{*}{$\begin{array}{l}\text { Riscos inerentes aos } \\
\text { produtos }\end{array}$} & \multirow{2}{*}{$\begin{array}{l}\text { Utiliza a gestão de } \\
\text { risco operacional } \\
\text { no processo } \\
\text { decisório }\end{array}$} & \multicolumn{2}{|c|}{$\begin{array}{l}\text { Realiza o monitoramento de } \\
\text { falhas não intencionais } \\
\text { relacionados aos seus produtos }\end{array}$} & \multirow[t]{2}{*}{$p$-valor } \\
\hline & & Sim & Não & \\
\hline & Sim & $45(97,8 \%)$ & $1(2,2 \%)$ & \multirow{2}{*}{0,006} \\
\hline & Não & $4(57,1 \%)$ & $3(42,09 \%)$ & \\
\hline & \multirow{2}{*}{$\begin{array}{l}\text { Utiliza a gestão de } \\
\text { risco operacional } \\
\text { no processo } \\
\text { decisório }\end{array}$} & \multicolumn{2}{|c|}{$\begin{array}{l}\text { Oferece produtos e serviços } \\
\text { adequados e formalizados }\end{array}$} & \multirow{2}{*}{$p$-valor } \\
\hline & & Sim & Não & \\
\hline & Sim & $45(97,8 \%)$ & $1(2,2 \%)$ & \multirow{2}{*}{0,043} \\
\hline & Não & $5(71,4 \%)$ & $2(28,6 \%)$ & \\
\hline
\end{tabular}

As práticas preventivas realizadas pelas empresas que obtiveram significância ao nível de $5 \%$ foram os riscos inerentes aos processos operacionais da empresa, e os riscos inerentes aos produtos das empresas.

Em relação aos riscos inerentes aos processos operacionais, dos 86,79\% que utilizam a gestão de risco operacional em seu processo decisório, 69,6\% também acompanham os riscos originados dos processos operacionais. Deste modo, infere-se que para as empresas pesquisadas, aquelas que utilizam a gestão de risco operacional tendem a também utilizar mecanismos de identificação e análise dos riscos inerentes às operações da empresa.

Já para os riscos relacionados aos produtos, verificou-se que a maioria das empresas que utiliza a gestão de risco operacional, tende a também realizar o monitoramento de falhas não intencionais relacionados aos seus produtos, e também oferecem produtos adequados e formalizados. 
Gestão de custos e formação de preço de venda, gestão de caixa e gestão de riscos: um estudo exploratório no arranjo produtivo local gesseiro do estado de Pernambuco Lucivaldo Lourenço da Silva Filho, Umbelina Cravo Teixeira Lagioia, João Gabriel Nascimento de Araújo, Juliana Gonçalves de Araujo, Francisco de Assis Carlos Filho

\section{CONCLUSÃO}

O presente estudo teve como objetivo geral investigar se os gestores do APL gesseiro do estado de Pernambuco conhecem, atribuem importância e utilizam as informações para a tomada de decisão gerencial, decorrentes da Gestão de Custos e Formação de Preços de Venda, Gestão de Caixa e Gestão de Risco Operacional.

Deste modo, conforme análise, concluiu-se que predominantemente os gestores não conhecem os conceitos de custo, disponibilidade de caixa, e risco operacional, mas atribuem um alto grau de importância para as variáveis estudadas, e as suas respectivas empresas de maneira geral utilizam a gestão de custos e formação do preço de venda, gestão de caixa e gestão de risco operacional em seu processo de tomada de tomada de decisão gerencial.

Devido à escassez de estudos (em congressos e periódicos nacionais de contabilidade) que abordem a mesma temática ou variáveis semelhantes em outros APLs, este trabalho teve como uma de suas principais limitações a falta de estudos publicados que permitissem a realização de uma análise comparativa. Outra limitação desse estudo foi à quantidade de empresas pesquisadas em detrimento a população que compõem o APL investigado, além do fato de ter sido feito uso de uma amostragem não probabilística, fazendo com que os resultados dessa pesquisa estejam restritos a amostra desse estudo. Essa restrição se dá ao fato do não conhecimento da real, tomando como base as empresas associadas à FIEPE. A generalização dos eventos e características, assim, estão restritas as empresas analisadas do APL gesseiro, não assumindo um caráter genérico de descrição.

Sugere-se para pesquisas futuras a realização de estudos com um número maior de variáveis a serem investigadas, o que permitirá um amplo entendimento do APL gesseiro. Assim como a realização de pesquisas semelhantes em outros arranjos produtivos locais do país, permitindo a realização de análise comparativa, a fim de possibilitar um confronto entre os resultados. 
Gestão de custos e formação de preço de venda, gestão de caixa e gestão de riscos: um estudo exploratório no arranjo produtivo local gesseiro do estado de Pernambuco Lucivaldo Lourenço da Silva Filho, Umbelina Cravo Teixeira Lagioia, João Gabriel Nascimento de Araújo, Juliana Gonçalves de Araujo, Francisco de Assis Carlos Filho

\section{REFERÊNCIAS}

ANDRADE, C. A. L.; FARIAS, C. J. L.; MOUTINHO, L. M. G. (2009). O Arranjo Produtivo Local do Gesso do Araripe-PE e sua relação com a ferrovia Transnordestina. In: VIII SOBER Nordeste. Pluralidades Econômicas, Sociais e Ambientais: interações para reinventar o Nordeste rural Parnaíba - PI. 2013. ASSAF NETO, A. Finanças Corporativas e Valor. 4. ed. São Paulo: Atlas.

BIS. (2004). International convergence of capital measurement and capital standards: a revised framework. Bank for International Settlements. Disponível em: http://www.bis.org.>. Acesso em: 29 jul 2013

BRAGA, R. Fundamentos e Técnicas de Administração Financeira. São Paulo: Atlas, 1995.

BRASILIANO, Antônio Celso Ribeiro. (2003). Manual de planejamento: gestão de riscos corporativos. São Paulo: Sicurezza.

CREPALDI, S. A. (2008). Contabilidade Gerencial. 4. ed. São Paulo: Atlas.

CUNHA, A. B.; BARBOSA, M. S. C.; FELISMINO, D. C.; DANTAS, I. C. (2008). Consumo da lenha na calcinação da gipsita e impactos ambientais no Pólo gesseiro da mesorregião do Araripe-PE. Revista de Biologia e Farmácia. v. 2, n. 1.

DAMODARAN, A. (2004). Finanças corporativas: teoria e prática. Porto Alegre. Bookman.

. (2010). Introdução à avaliação de investimentos: ferramentas e técnicas para a determinação do valor de qualquer ativo. 2. ed. Rio de Janeiro: Qualitymark.

DANTAS, J. A.; SILVA, C. A. T.; SANTANA, C. M.; VIEIRA, E. T. (2011). Padrões de comunicação científica em contabilidade: um comparativo entre a Revista Contabilidade e Finanças e a The Accounting Review. Revista Contemporânea de Contabilidade, Florianópolis, v.8, n. 16, p. 11-36, jul./dez.

DIAS, Sérgio R. (Coord.). (2006). Gestão de marketing. 5. tiragem. São Paulo: Saraiva.

DIEZ-VIAL, I. (2011). Geographical cluster and performance: The case of Iberian ham. Food Policy, v. 36, p. 517-525, jun.

DUARTE Jr., A. M. (2001). Riscos: definições, tipos, medição e recomendações para seu gerenciamento - gestão de risco e derivativos. São Paulo: Atlas. 
Gestão de custos e formação de preço de venda, gestão de caixa e gestão de riscos: um estudo exploratório no arranjo produtivo local gesseiro do estado de Pernambuco Lucivaldo Lourenço da Silva Filho, Umbelina Cravo Teixeira Lagioia, João Gabriel Nascimento de Araújo, Juliana Gonçalves de Araujo, Francisco de Assis Carlos Filho

FALCÃO, V. L. C. (2009). Política de desenvolvimento territorial: A Experiência do Fórum Territorial do Araripe (Fotear). In: Küster, A; Marti J. F. (Org.). Políticas públicas para o semi-árido: experiências e conquistas no nordeste do Brasil. Fortaleza: Fundação Konrad Adenauer.

FREZATTI, F. (1997). Gestão do Fluxo de Caixa Diário. São Paulo: Atlas.

GALDÁMEZ, E. V. C.; CARPINETTI, L. C. R.; GEROLAMO, M. C. (2009). Proposta de um sistema de avaliação do desempenho para arranjos produtivos locais. Gestão de Produção, São Carlos, v. 16, n. 1, p. 133-151, jan.-mar.

GIL, Antônio Carlos. (2002). Como elaborar projetos de pesquisa. 4 ed. São Paulo, SP: Atlas.

GITMAN, L. J. (2001). Princípios de Administração Financeira. São Paulo: Ed. Harbra.

HALL, R. J.; COSTA, V. C.; KREUZBERG, F.; MOURA, G. D.; HEIN, N. (2012). Contabilidade como uma ferramenta da gestão: um estudo em micro e pequenas empresas do ramo de comércio de Dourados-MS. Revista da Micro e Pequena Empresa, Campo Limpo Paulista, v. 6, n. 3, p.4-17, set/dez.

HOJI, M. (2003). Administração Financeira: uma abordagem prática: matemática financeira aplicada, estratégias financeiras, análise, planejamento e controle financeiro. São Paulo: Atlas.

INSTITUTO BRASILEIRO DE GEOGRAFIA E ESTATÍSTICA. (2012). Vinculado ao Ministério do Planejamento, Orçamento e Gestão. Disponível em: <http://www.ibge.gov.br/>. Acesso em: 5/jul/2012.

JORION, P. (2003). Value at risk: a nova fonte de referências para gestão de risco financeiro. 2. ed. São Paulo: Bolsa de Mercadorias \& Futuros (BM\&F).

KUKALIS, Sal. (2010). Agglomeration Economies and Firm Performance: The Case of Industry Clusters. Journal of Management, v. 36, n. 2, p. 453-481, mar.

LUZ, A. B.; LINS, F. A. F. (2005). Rochas \& Minerais Industriais - CETEM - MCT Centro de Tecnologia Mineral - Ministério da Ciência e Tecnologia, Rio de Janeiro.

MAHER, M. (2001). Contabilidade de custos. São Paulo: Atlas.

MARION, José Carlos (Coord.). (1996). Contabilidade e controladoria em agribusiness. São Paulo: Atlas. 
Gestão de custos e formação de preço de venda, gestão de caixa e gestão de riscos: um estudo exploratório no arranjo produtivo local gesseiro do estado de Pernambuco Lucivaldo Lourenço da Silva Filho, Umbelina Cravo Teixeira Lagioia, João Gabriel Nascimento de Araújo, Juliana Gonçalves de Araujo, Francisco de Assis Carlos Filho

MARSHALL, Alfred. (1982). Princípios de Economia in Os Economistas. Primeira Edição, São Paulo: Abril Cultural, (original publicado em 1890).

MARSHALL, C. (2002). Medindo e gerenciando riscos operacionais em instituições financeiras. Qualitymark, RJ.

MARTINS, Eliseu. (2008). Contabilidade de custos. 9. ed. São Paulo: Atlas.

MATIAS, A. B.; LOPES JÚNIOR, F. (2002). Administração financeira nas empresas de pequeno porte. São Paulo: Manole.

MATOS, F. R. N.; MACHADO, D. Q. (2013). Ação empreendedora em um APL: O porte da empresa como estilo de gestão. Revista Pensamento \& Realidade. Ano XVI, v. 28, n. 2.

MINISTÉRIO DO DESENVOLVIMENTO, INDÚSTRIA E COMÉRCIO EXTERIOR. Arranjos produtivos locais. Disponível em:

$<$ http://www.desenvolvimento.gov.br/sitio/interna/interna.php?area=2\&menu=300>. Acesso em: 29/ago/2012.

MINISTÉRIO DO DESENVOLVIMENTO, INDÚSTRIA E COMÉRCIO EXTERIOR. (2013). Relação dos Núcleos Estaduais de APLs no Brasil. Disponível em: $<$ www.mdic.gov.br/sitio/interna/interna.php?area=2\&menu=3008>. Acesso em: 15/nov/ 2013.

MUNARETTO, L. F.; CORRÊA, H. L.; CUNHA, J. A. C. (2013). Um estudo sobre as características do método Delphi e de grupo focal, como técnicas na obtenção de dados em pesquisas exploratórias. Revista de Administração. UFSM, Santa Maria, v. 6, n. 1, p. 09-24, jan./mar.

OLIVEIRA, M. A.; ALVES, C. L. C. (2012). Política de Preços no Desempenho de Empresas: um estudo com simulador organizacional de estratégia. Sociedade, Contabilidade e Gestão, Rio de Janeiro, v. 7, n. 1, jan./jun.

OLIVEIRA, A. M. B.; RAMALHO, R. O.; MOURA, A. A. F. (2013). Gestão de Capital de Giro Líquido e de Fluxo de Caixa em Risco de Empresas de Bens Industriais Listadas na BM\&FBovespa. Revista de Contabilidade da UFBA, v. 7, n. 2.

PADOVEZE, C. L. (2011). Controladoria Estratégica e Operacional. 2. ed. São Paulo: Cengage Learning. 
Gestão de custos e formação de preço de venda, gestão de caixa e gestão de riscos: um estudo exploratório no arranjo produtivo local gesseiro do estado de Pernambuco Lucivaldo Lourenço da Silva Filho, Umbelina Cravo Teixeira Lagioia, João Gabriel Nascimento de Araújo, Juliana Gonçalves de Araujo, Francisco de Assis Carlos Filho

PELISSARI, A. S.; GONZALEZ, I. V. D. P.; VANALLE, R. M.. (2011). Competências gerenciais: Um estudo em pequenas empresas de Confecções. Revista Eletrônica de Administração, v. 17, n. 1, p.149-180.

PLEWA, J. F. JR.; FRIEDLOB, T. G. (1995). Finance fundamentals for nonfinancial managers series understanding cash flow.

PORTER, M. E. (1998). Clusters and the new economics of competition. Harvard Business Review. v. 76, n. 6, p. 77-90, nov./dez.

REDE DE PESQUISA EM SISTEMA E ARRANJOS PRODUTIVOS E INOVATIVOS LOCAIS. (2012). Rede de Pesquisa Interdisciplinar no Instituto de Pesquisa da Universidade Federal do Rio de Janeiro. Disponível em: <http://www.redesist.ie.ufrj.br/>. Acesso em: 10 ago.

REIS, R. G. B.; SANTANA, A. F. B. (2012). Formação de preço de venda e a Relação de Custo x Volume x Lucro: Um Estudo de Caso em uma empresa de confecções. Revista Eletrônica Saber Contábil. v. 2, n. 2, mai./ago.

SANTOS, G. A. G.; DINIZ, E. J.; BARBOSA, E. K. (2004). Aglomerações, arranjos produtivos locais e vantagens competitivas locacionais. Revista do BNDES, Rio de Janeiro, v. 11, n. 22, p. 151-179, dez.

SANTOS, R. V. (1999). Modelagem de sistemas de custos. Revista do Conselho Regional de Contabilidade de São Paulo. São Paulo, ano IV, n. 7, p. 62-74, abr.

SANVICENTE, A. Z. (1997). Administração Financeira. 3. ed. São Paulo: Atlas.

SEBRAE - Serviço Brasileiro de Apoio às Micro e Pequenas Empresas. (2006). Estudo de caracterização econômica do polo de confecções do agreste de Pernambuco. Disponível em: <http://www.pe.sebrae.com.br>. Acesso em: 15/abr/2013.

SEBRAE. (2012). Disponível em: <http://www.sebrae.com.br/momento/quero-melhorarminha-empresa/utilize-as-ferramentas/formacao-de-precos/integra_bia/ident_unico/36>. Acesso em: 30/ago.

SEBRAE. (2013). Termo de Referência para atuação do Sistema SEBRAE em Arranjos Produtivos Locais. Disponível em: <http:// www.sebrae.org.br>. Acesso em: 19/mai.

SINDUSGESSO. (2012). Sindicato da Indústria do Gesso. Disponível em: <http://www.sindusgesso.org.br/>. Acesso em: 30/ago. 
Gestão de custos e formação de preço de venda, gestão de caixa e gestão de riscos: um estudo exploratório no arranjo produtivo local gesseiro do estado de Pernambuco Lucivaldo Lourenço da Silva Filho, Umbelina Cravo Teixeira Lagioia, João Gabriel Nascimento de Araújo, Juliana Gonçalves de Araujo, Francisco de Assis Carlos Filho

SÖRVELL, O. (2009). Clusters - Balancing Evolutionary and Constructive Forces. 2. ed., Odeshog: Danagards Grafiska.

STAINSACK, Cristiane. (2005). Arranjos Produtivos Locais. Curitiba: IEL.

STICKNEY, C. P.; WEIL, R. L. (2001). Contabilidade Financeira: uma introdução aos conceitos, métodos e usos. São Paulo: Atlas.

Data de Submissão: 14/05/2015

Data de Aceite: 15/03/2016 